\title{
Assessing knowledge of lady health workers regarding sexually transmitted infections in rural Pakistan
}

\author{
Rehana Khalil $^{1 *}$, Mohammad Ali Chang ${ }^{2}$, Zahid Naeem ${ }^{3}$
}

\begin{abstract}
${ }^{1}$ Department of Family and Community Medicine, Unaizah College of Medicine, Qassim University, Saudi Arabia ${ }^{2}$ Department of Community Medicine, Baqai Medical University, Karachi, Pakistan

${ }^{3}$ Department of Family and Community Medicine, College of Medicine Buraidah, Qassim University, Saudi Arabia
\end{abstract}

Received: 26 July 2016

Accepted: 26 August 2016

\section{*Correspondence:}

Dr. Rehana Khalil,

E-mail: rehana.noman@ucm.edu.sa

Copyright: () the author(s), publisher and licensee Medip Academy. This is an open-access article distributed under the terms of the Creative Commons Attribution Non-Commercial License, which permits unrestricted non-commercial use, distribution, and reproduction in any medium, provided the original work is properly cited.

\section{ABSTRACT}

Background: In a conservative culture with limited social mobility like Pakistan, a lady health worker (LHW) provides a valuable opportunity for women with STIs to be diagnosed early, referred for appropriate treatment, and can counsel regarding further prevention. The study was intended to assess LHWs knowledge regarding early assessment and referral of women with STIs in a rural area of Pakistan.

Methods: This descriptive cross sectional study was conducted at health centers in a district of interior Sindh, Pakistan called Badin. A sample of 105 lady health workers were recruited using systemic random sampling technique, during six months from September 2015 to March 2016. Data were collected through a semi-structured questionnaire and analyzed using IBM SPSS version 22 and Microsoft excel.

Results: Majority (29\%) of LHWs were aged between 25 and 29 years. Half sample (51\%) of LHWs were educated up to middle school and $6 \%$ were intermediate. Eighty-five percent respondents were married. More than half (59\%) of LHWs were trained regarding STIs and 21.9\% got the special training for it. Among them, 59\% of respondents defined STIs correctly. Two thirds (67.6\%) of participants knew the meaning of safe sex. One third (37\%) of sample was aware of complications due to STIs during pregnancy. Two fifth of LHWs (40\%) stated to refer the women with suspected STIs to the hospital for confirmation and further intervention. Near half of LHWs (48\%) recommended the use of condom for prevention.

Conclusions: The current study concludes that there are gaps in knowledge of LHWs regarding STIs which makes it unsatisfactory. Therefore in service periodical sensitization and advocacy workshops and trainings of these LHWs are recommended to fill information gaps, remove misinformation and provide quality information in a way that is linked to the women's reproductive health in Pakistan.

Keywords: Knowledge of LHWs, STIs, Rural women

\section{INTRODUCTION}

Pakistan is the second most populous Muslim-majority country. Religious and social ethics are highly admired and deeply ingrained in the Pakistani society. Many people in Pakistan are severely disadvantaged in terms of income, education, power structure, or gender. The majority of the population, 69\%, is rural. Poverty is widespread $31 \%$ of Pakistanis subsist on US\$1 per day, and $85 \%$ earn less than US\$2 per day. All these factors are compounded by cultural practices. Pakistan is a maledominated society, and prejudice against women is reflected in the higher female mortality rate and low literacy rate. This combination of factors gives rise to strong negative repercussions on health of women. ${ }^{1-5}$ To make things worse, reproductive tract infections (RTIs) in many cases are asymptomatic among women, making their detection and diagnosis difficult. Uninfected women 
are more susceptible to acquire an infection from infected male partner than an uninfected male from an infected woman. Despite grave consequences, policy makers and health planners in developing countries have not given much attention to these infections. In part, it is due to the misconceptions that RTIs are not fatal, are expensive to treat, and that they affect only a particular segment of population, such as commercial sex workers. ${ }^{6}$ RTIs are of demographic significance as they are intertwined with safe motherhood, family planning and child survival. These consequences range from less serious to fatal outcomes for the maternofoetal health, such as, premature delivery, low birth weight, still births, congenital syphilis, neo-natal conjunctivitis, neurological and cardiovascular diseases, PID, infertility, and ano-genital cancers, specifically cervical cancer. ${ }^{8}$ These consequences could be particularly confounding in most developing countries where woman's status in the society, and even within the family, is usually dependent on her fertility.

Not all sexually transmitted infections (STIs) are reproductive tract infections, nor are all reproductive tract infections sexually transmitted but most of the STIs lead to RTIs. These infections represent a major global health problem leading to morbidity, mortality and stigma. Control of STIs has been given priority since the advent of the HIV/ AIDS epidemic, in recognition of their role in facilitating the sexual transmission of HIV., ${ }^{1,9,10}$ Timely healthcare seeking by individuals and appropriate case management can reduce the duration of infectivity in sexually active individuals and are, therefore, important determinants of STI control. ${ }^{11-13}$ In Pakistan, as in many other low-income countries, case management for STIs is usually sub-optimal due to rampant personal empiricism and inappropriate practices. ${ }^{14-17}$

In a conservative culture with limited social mobility, a community health worker provides a valuable opportunity for women with STIs to be diagnosed early referred for appropriate treatment, and can counsel regarding further prevention. Community health workers are the backbone of the primary health care. ${ }^{18}$ In our country, community health workers are known as Lady Health Workers (LHW) and are working under the National Program for Family Planning and Primary Health Care. It was launched in Pakistan in 1994..$^{19,20}$ This program was designed to provide health services to the community at their doorsteps. The importance of LHWs in the field of health cannot be overlooked because they are the solitary means of house-to-house access of health system for the provision of basic health care because of their acceptability. ${ }^{21}$ Hence it is very important to study whether they are capable of delivering the required services. With this backdrop the present study has been carried out to assess their knowledge regarding STIs for early assessment and referral of women with STIs.

\section{METHODS}

A quantitative approach using a descriptive survey design was chosen for the study.

\section{The instrument}

A semi-structured questionnaire was developed following an extensive literature review on the topic which ensured validity and reliability of the questionnaire. The sociodemographic details included the age of LHWs, qualification and marital status. Other variables were regarding the assessment of knowledge of the participants, which was assessed through 21 questions included identification of types of STIs, prevention, safe sex and their source of knowledge etc.

\section{Subjects}

The participants were recruited using systemic random sampling technique. All 105 lady health workers working at Health Centres in a district of interior Sindh, Pakistan called Badin, during six months from September 2015 to March 2016, and who were willing to participate, were included in the study.

\section{Pilot}

A pretest of the questionnaire was conducted with ten LHWs who met the inclusion criteria. The purpose of the pilot was to test the clarity and relevance of the questionnaire. The responses from the pilot study were checked for completeness and consistency by the principal investigator. In order to avoid response biases, the participants in the pilot study were not included in the main survey.

\section{Validity and reliability}

The questionnaire was developed in English first and its content validity was assessed by two co-investigators. Then it was translated into Sindhi, the local language of Badin, and validated by co-researchers. Five data collectors were trained by the principal investigator for data collection. The reliability of the instrument was tested using Cronbach's coefficient alpha, and the overall consistency of the instrument was found to be 0.61 .

\section{Ethical considerations}

Informed verbal consent was obtained prior to each interview. Participation was voluntary and no coercion was used in the data collection process. Respondents were fully informed of the nature of the study and the use of the data. They were free to withdraw from the interview at any stage or refuse to answer any particular question. Participants were also ensured of confidentiality. No personal identifying information was obtained for any part of the investigation. 


\section{Data analysis}

After completion of data collection, each questionnaire was checked for completeness and consistency by the principal investigator before entering the data. The data were entered and analyzed using, Microsoft Excel and IBM SPSS VERSION for Windows 22.0 software.

\section{RESULTS}

Table: 1: Descriptive statistics of respondents $(n=105)$.

\begin{tabular}{|c|c|c|}
\hline Age category & Frequency & Percent \\
\hline $25-29$ years & 30 & 28.6 \\
\hline $30-34$ years & 29 & 27.6 \\
\hline $35-39$ years & 14 & 13.3 \\
\hline 40-44 years & 16 & 15.2 \\
\hline $45-49$ years & 11 & 10.5 \\
\hline$>50$ years & 5 & 4.8 \\
\hline Educational status & Frequency & Percent \\
\hline Middle school & 54 & 51.4 \\
\hline Metric & 45 & 42.9 \\
\hline Intermediate & 6 & 5.7 \\
\hline Marital status & Frequency & Percent \\
\hline Married & 89 & 84.7 \\
\hline Divorced & 7 & 6.7 \\
\hline Widowed & 5 & 4.8 \\
\hline Separated & 4 & 3.8 \\
\hline Total & 105 & 100 \\
\hline
\end{tabular}

Table 2: Knowledge of STIs $(n=105)$.

\begin{tabular}{|c|c|c|}
\hline \multicolumn{3}{|l|}{ Definition of STIs } \\
\hline Response & Frequency & Percent \\
\hline $\begin{array}{l}\text { Infection and sexual } \\
\text { transmission }\end{array}$ & 62 & $59 \%$ \\
\hline Genital infection & 10 & $9.5 \%$ \\
\hline Some sort of infection & 15 & $14.4 \%$ \\
\hline Don’t know & 8 & $7.6 \%$ \\
\hline Didn't answer & 10 & $9.5 \%$ \\
\hline \multicolumn{3}{|c|}{ Source of Information regarding STIs } \\
\hline Response & Frequency & Percent \\
\hline Got special training & 23 & $21.9 \%$ \\
\hline A part of official training & 62 & $59 \%$ \\
\hline Media & 20 & $19.1 \%$ \\
\hline \multicolumn{3}{|l|}{ Knowledge of safe sex } \\
\hline Response & Frequency & Percent \\
\hline Yes & 71 & $67.6 \%$ \\
\hline No & 34 & $32.4 \%$ \\
\hline \multicolumn{3}{|c|}{$\begin{array}{l}\text { Knowledge about complication of STIs during } \\
\text { pregnancy }\end{array}$} \\
\hline Response & Frequency & Percent \\
\hline Yes & 39 & $37.1 \%$ \\
\hline No & 63 & $60 \%$ \\
\hline Don't know & 3 & $2.9 \%$ \\
\hline Total & 105 & 100 \\
\hline
\end{tabular}

Table 1 shows the demographic profile of the study participants. A total of 105 lady health workers were interviewed. Majority (29\%) of LHWs were aged between 25 and 29 years. Education level of the majority (51\%) LHWs were up to middle school and only $6 \%$ were intermediate. Eighty-five percent respondents were married.

The data organized in Table 2, discloses that $59 \%$ of LHWs conveyed that they were given information regarding STIs including its signs/symptoms, discharge and examination, during their official training for health workers while $21.9 \%$ claimed to get the special training for it. Among them, 59\% of respondents defined STIs as sexually transmitted infection, $9.5 \%$ identified it as a genital infection and $14.4 \%$ said they are some sort of infections without specifying it. Almost Two thirds $(67.6 \%)$ of participants understood the meaning of safe sex. Only one third $(37 \%)$ of sample was aware of complications due to STIs/RTIs during pregnancy.

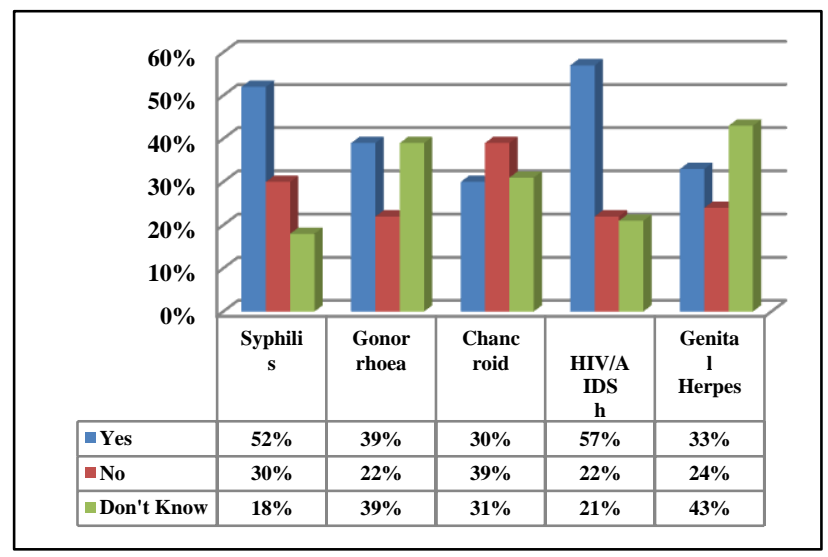

Figure 1: Infections Identified as STIs by respondents $(\mathbf{n}=\mathbf{1 0 5})$.

Figure 1, reveals that more than half of the sample (57\%) had good knowledge about HIV/AIDS, 52\% respondents had knowledge about Syphilis, 39\% knew about gonorrhea while chanchroid and genital herpes were known by $33 \%$ and $30 \%$ LHWs respectively.

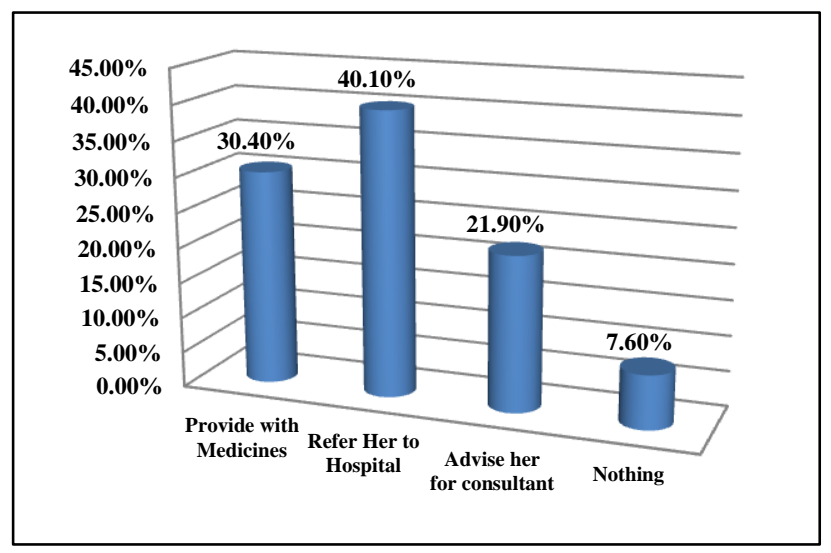

Figure 2: Handling of STI patient $(n=105)$ 
Two fifth of LHWs (40\%) stated that they would refer the women with suspected STIs to the hospital for confirmation and further intervention, while $30 \%$ were of the opinion that the suspected STI patient should be given medicines at their door without delay, $22 \%$ said they have to advice the patient to consult some consultant specialized in STIs in the vicinity and $8 \%$ of LHWs said there is no need of any intervention as STIs are not harmful for health Figure 2.

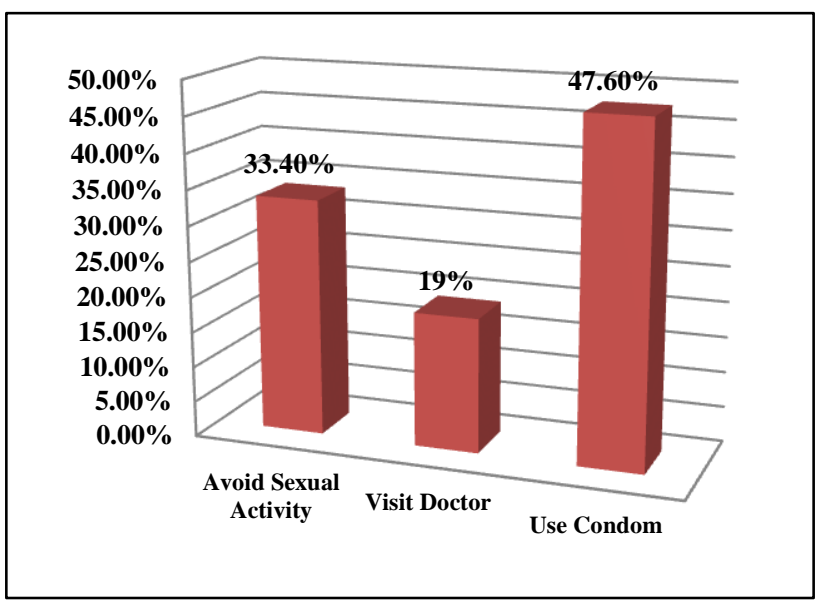

Figure 3: Prevention of STI $(n=105)$.

Nearly half of all LHWs (48\%) stated, they would recommend the use of condom to prevent the transmission of STIs among women, 33\% insisted on avoidance of sexual activity while $19 \%$ supported the idea that all ladies who are really concerned should visit their doctors Figure 3.

\section{DISCUSSION}

To provide awareness on prevention and control of HIV/AIDS and STDs is one of the stipulated tasks of LHWs. $^{22}$ The present study has been carried out to assess their knowledge regarding STIs for early assessment and referral of women with STIs in a rural area of Pakistan.

Recruitment of LHWs is followed by 15 months of basic training at the first level care facility (basic health unit and rural health center) or tehsil headquarter hospital, by the staff working over there in two phases, using Programme training manuals and curriculum. The first phase of basic training is of five days a week for three months. The second phase of training lasts for 12 months with three weeks of field work followed by one week of classroom training each month. The basic training of the LHWs is complemented by one day "continuing education session" each month and 15 days "refresher training" on various topics every year. ${ }^{22}$ According to the findings of our study $59 \%$ of LHWs stated that they were educated regarding STIs including its signs/symptoms, discharge and examination, during their official training for health workers and $21.9 \%$ claimed to get the special training for it but apart from $59 \%$ of respondents who correctly defined STIs as sexually transmitted infection, rest were unable to define STIs. Almost two thirds of participants understood the meaning of safe sex. Only one third of sample was aware of complications due to STIs/RTIs during pregnancy. Our data shows, more than half of the sample had good knowledge about HIV/AIDS and syphilis, 39\% knew about gonorrhea while chanchroid and genital herpes were known by $33 \%$ and $30 \%$ LHWs respectively. There are studies on sexually transmitted infection care in Pakistan from the providers' perspective but unfortunately there is paucity of data of evaluation of LHWs regarding their serves in connection to STIs in women of Pakistan. ${ }^{23}$ So the findings of current study cannot be compared with any data of similar health issue. External evaluation in the year 2009 shows that LHWs' clinical knowledge has enhanced since the $3^{\text {rd }}$ Evaluation, however, there is still room for improvement. $^{24}$

Two fifth of sample LHWs stated that they would refer the women with suspected cases of STIs to the hospital for confirmatory tests and proper treatment, while rest had different opinions. Nearly half of the LHWs stated, they would recommend the use of condom to prevent the transmission of STIs but the other half sample was not sure about the proper preventive measures. The LHW's serve as a link between community and health facilities, providing both preventive and curative care. ${ }^{24,25}$ LHW's are an vital resource for countries like Pakistan, and maintaining procedural standards and guidelines would facilitate a thriving programme, which requires to be monitored and evaluated. First evaluation of this program was carried out in 1995. According to that report, $83 \%$ LHWs were having good knowledge regarding preventive activities. The second evaluation of this program was carried out in 1996; according to which 96\% LHWs had established their health houses. Majority of lady health workers were found to be satisfactory in providing maternal care. ${ }^{26}$ The third report was initiated in 1999 and completed in 2002. It was carried out by Oxford Policy Management, UK. It demonstrated that the performance of about $17 \%$ of LHW's was poor and $35 \%$ were below average. ${ }^{27}$

The inadequacies demonstrated through our study are very sensitive flaws and are very essential ones too, that are required to be addressed. The low level of knowledge displayed in case of STIs/RTIs can be rectified by additional extensive trainings in this regard to strengthen the capabilities of LHWs to promote reproductive health among Pakistani women specially the rural women.

The limitations of this study were participation in the study was voluntary so the data gathered for this study may not be generalized.

\section{CONCLUSION}

There are gaps in knowledge regarding STIs among LHWs which emphasize on further in-depth training to 
improve their abilities and for subsequent guidance of the women with suspected STIs. Therefore in service periodical sensitization and advocacy workshops and trainings of these LHWs are recommended to fill information gaps, remove misinformation and provide quality information in a way that is linked to the women's reproductive health in rural areas of Pakistan.

\section{ACKNOWLEDGEMENTS}

Authors acknowledge the immense help received from the scholars whose articles are cited and included in references of this manuscript. The authors are also grateful to authors/editors/publishers of all those articles, journals and books from where the literature for this article has been reviewed and discussed.

Funding: No funding sources

Conflict of interest: None declared

Ethical approval: The study was approved by the Institutional Ethics Committee

\section{REFERENCES}

1. Ayres RU. London: Earthscan Publications, 1998. Turning point: An end to the growth paradigm; 1998:63.

2. Ministry of Economic Affairs and Statistics. Official Pakistani population clock. Available at http://www.statpak.gov.pk/depts/pco/. Accessed on 11 February 2010.

3. Population Census Organization of Pakistan. Population size and growth of major cities, 1998 census. Available at http://www.statpak.gov.pk/depts/pco/statistics/pop_ major_cities/pop_major_cities.html. Accessed on 11 February 2010.

4. City District Government of Faisalabad. Population. Available at http://www.faisalabad.gov.pk/statistics.aspx?task=po p. Accessed on 10 April 2007.

5. Jawad F. Diabetes in Pakistan. Diabetes Voice. 2003;48:12-4.

6. Reproductive Tract Infections among Women in Pakistan: An urban case study By Durr-e-Nayab. Accessed on 2016. Available at www.pide.org.pk/.../Reproductive\%20Tract\%20Infe ctions\%20among\%20Women\%2. Accessed on 10 April 2007.

7. AVSC-International. National Guideline for the Management of Reproductive Tract Infections; 1999.

8. Shefer T, Strebel A, Wilson T, Shabalala N, Simbayi L, Ratele K, et al. The social construction of sexually transmitted infections (STIs) in South African communities. Qual Health Res. 2002;12:1373-90.

9. Wasserheit JN. Epidemiologic synergy: Interrelationships between human immunodeficiency virus infection and other sexually transmitted diseases. Sex Transm Dis. 1992;19:61-77.
10. Fonck K, Mwai C, Rakwar J, Kirui P, NdinyaAchola JO, Temmerman M. Healthcare-seeking behavior and sexual behavior of patients with sexually transmitted diseases in Nairobi, Kenya. Sex Transm Dis. 2001;28:367-71.

11. Moses S, Ngugi EN, Bradley JE, Nieru EK, Ehdridge G, Mua E, et al. Health care-seeking behavior related to the transmission of sexually transmitted diseases in Kenya. Am J Public Health. 1994;84:1947-51.

12. Mayaud P, Mosha F, Todd J, Baliea R, Mgara J, West B, et al. Improved treatment services significantly reduce the prevalence of sexually transmitted diseases in rural Tanzania: results of a randomized controlled trial. AIDS 1997;20:1873-80.

13. Khandwalla HE, Luby S, Rahman S. Knowledge, attitudes, and practices regarding sexually transmitted infections among general practitioners and medical specialists in Karachi, Pakistan. Sex Transm Infect. 2000;76:383-5.

14. Voeten HA, Otido JM, O'hara HB, Kuperus AG, Borsboom GJ, Ndinya-Achola JO, et al. Quality of sexually transmitted disease case management in Nairobi, Kenya: a comparison among different types of healthcare facilities. Sex Transm Dis. 2001;28:633-42.

15. Sihavong A, Lundborg CS, Syhakhang L, Vernby A, Panyanouvang A, Marions L, et al. Health providers' competence in the management of reproductive tract infections in Vientiane, Lao People's Democratic Republic. Int J STD AIDS. 2007;18:774-81.

16. Mayaud P, Mabey D. Approaches to the control of sexually transmitted infections in developing countries: old problems and modern challenges. Sex Transm Infect. 2004;80:174-82.

17. Declaration of Alma Ata, International conference on Primary Health Care, Alma-Ata, USSR. 1978;6-12.

18. Majumdar B, Amarsi Y, Carpio B. Pakistan's community health workers. Can Nurse. 1997;93:324.

19. Afsar HA, Younus M. Recommendations to strengthen the role of lady health workers in national program for family planning and primary health care in Pakistan: The health workers perspective. J Ayub Med Coll. 2005;17:48-53.

20. Butt MA. Skilled health workers: a solution to primary health problems in Pakistan. Middle East $\mathbf{J}$ Family Med. 2006;4:1-4.

21. Douthwaite M, Ward P. Increasing contraceptive use in rural Pakistan: an evaluation of the lady health worker program. Health Policy and Planning. 2005;20:117-23.

22. Hafeez A, Mohamud BK, Shiekh MR, Shah SAI, Jooma R. Lady health workers programme in Pakistan: challenges, achievements and the way forward. J Pak Med Assoc. 2011;61(3):210-5.

23. Khan AA, Khan A. Sexually transmitted infection care in Pakistan: The providers perspective. 2012;62:9. 
24. Oxford policy management. Summary of results. Lady health workers programme. External evaluation of a national programme for family planning and Primary Health care, UK, 2009. Available at http://www.opml.co.uk/

policy_areas/statistics/quantitative_

information_for_policy_and_programme/

6241_lhw.html. Accessed on 3 April 2007.

25. Government of Pakistan. Ministry of Health. National health Policy 2009. Steeping towards better health. Pakistan, 2009. Available at http://www.gcappakistan.net/Downloads/ health_policy_zero_draft19-Feb-2009.pdf. Accessed on 2 May 2010.

26. PM's program for family planning and PHC. Second evaluation report. Federal PIU, Ministry of Health, Government of Pakistan; 1996.

27. External evaluation report. National program for family planning and primary health care. Oxford Policy Management; 2002.

Cite this article as: Khalil R, Chang MA, Naeem Z. Assessing knowledge of lady health workers regarding sexually transmitted infections in rural Pakistan. Int J Reprod Contracept Obstet Gynecol 2016;5:3372-7. 